\title{
Diversificação dos sistemas produtivos familiares: reflexões sobre as relações sociedade-natureza na Amazônia Oriental
}

\section{Diversification of Family Production Systems: refletions on nature- society relations in the Eastern Amazon}

Myriam Cyntia Cesar de Oliveira - Doutora em Desenvolvimento Rural pela Universidade Federal do Rio Grande do Sul. Professora-pesquisadora do Núcleo de Ciências Agrárias e Desenvolvimento Rural da Universidade Federal do Pará (UFPA). E-mail: myriam@ufpa.br

Jalcione Almeida - Doutor em Sociologia pela Université de Paris 10. Professor Associado do Departamento de Sociologia, da Universidade Federal do Rio Grande do Sul (UFRGS). E-mail: jal@ufrgs.br

Luis Mauro Santos Silva - Doutor em Ciências, Universidade Federal de Pelotas. Professor-pesquisador do Núcleo de Ciências Agrárias e Desenvolvimento Rural da Universidade Federal do Pará (UFPA). E-mail:lmsilva@ufpa.br

\section{Resumo}

Este artigo tece algumas reflexões sobre as relações sociedade-natureza na Amazônia, a partir das mudanças para a diversificação que está ocorrendo no sudeste paraense. Partindo de um olhar sobre os caminhos da agricultura, procurou-se situar como os tipos de relações com natureza influenciaram nas formas de exploração adotadas na região e o que significam essas mudanças em termos das relações entre agricultores e o meio natural. O texto discute os principais elementos e motivações que estão na constituição desse processo de diversificação, estabelecendo uma relação do mesmo com a capacidade de adaptação e com a mudança de projetos dos agricultores no sentido da permanência. Nesse sentido, essa mudança parece ilustrar a existência do mesmo processo de estabilização relativa dos agricultores, já identificado em outras fronteiras.

\section{Palavras-chave}

Amazônia. Agricultura familiar. Diversificação. Estabilização.

\begin{abstract}
This article weaves some reflections on the relations society-nature in the Amazon region from the changes for the diversification that is taking place in the south-east from Pará. Leaving from a glance on the ways of the agriculture, it was tried to situate like the types of relations with nature they influenced the forms of exploration adopted in the region and what these changes mean in terms of the relations between farmers and the natural environment. The text discusses the principal elements and motivations that are in the constitution of this process of diversification, establishing a relation of the same thing with the capacity of adaptation and with the change of projects of the farmers in the sense of the permanence. In this sense, it seems to this change to illustrate the existence of the same process of relative stabilization of the farmers, already identified in other frontiers.
\end{abstract}

\section{Keywords}

Amazon. Small farmer. Diversification. Stabilization. 


\section{INTRODUÇÃO}

Há décadas prevalecem nas fronteiras amazônicas dinâmicas de ocupação do espaço baseadas em formas agressivas de exploração do ambiente, às quais se associam vários problemas. As relações historicamente estabelecidas entre sociedade e natureza nessas áreas revelam a predominância de uma visão moderna que geralmente reduz os elementos naturais existentes a uma condição de "recursos" e de uma disputa pela posse e uso dos mesmos, tendo em vista os diferentes interesses que orientam os diversos atores locais.

À semelhança de outras áreas de fronteira, no sudeste paraense essa disputa e essa visão foram determinantes na definição do ritmo e do padrão de exploração do meio natural. A ideia de que áreas de florestas eram espaços improdutivos e subdesenvolvidos e de que a legitimação da posse da terra se associava à remoção da vegetação como demonstração de aplicação de trabalho ("beneficiamento da terra”), apoiada pela implementação de políticas orientadas para a consolidação da atividade de pecuária extensiva, influenciou para o estabelecimento de uma dinâmica hegemônica de relações entre sociedade e natureza cujos efeitos se expressaram na homogeneização das paisagens e simplificação dos sistemas de produção.

No caso dos agricultores familiares, diferentemente de outros atores, a adoção dessa forma de exploração do meio natural baseada no desmatamento e implantação de pastagens e, consequentemente, sua participação no processo de transformação das paisagens não se orientou por uma visão da natureza enquanto geradora de lucro. Para os agricultores da fronteira, a importância da natureza estava na relação que estabeleciam entre a disponibilidade de matérias-primas e principalmente da terra - entendida como meio de trabalho e de produção e como lugar onde se materializam as relações sociais (DIEGUES, 2004) - e a garantia da reprodução social da família.

No entanto, em inúmeros casos tal relação de dependência não colocou barreiras aos agricultores para utilizarem até a exaustão o meio natural de seus estabelecimentos agrícolas. As condições socioeconômicas desfavoráveis que caracterizavam a região no passado, sobretudo o quadro altamente instável da situação fundiária, limitavam a capacidade das famílias em desenvolver outras formas de exploração. Nessas bases, as estratégias eram definidas de maneira que a preservação do meio natural e a permanência no espaço eram colocadas em segundo plano ou até mesmo preteridas em nome da reprodução social.

Essa dinâmica das relações sociedade-natureza, especialmente entre agricultores familiares e seu ambiente, predominou durante anos no sudeste paraense. Contudo, apesar do vigor que tinha (e que ainda tem), ela nunca foi única, 
nem exclusiva. Existia uma diversidade interna que não encontrava oportunidades para se sobressair, mas que já apontava que nem todos os agricultores optaram pela via da simplificação de seus sistemas de produção, nem todas as localidades seguiram a mesma trajetória da homogeneização da paisagem.

Atualmente, observa-se que essa diversidade ambiental existente na região vem sendo reforçada e ampliada. As transformações ocorridas no contexto socioeconômico regional nos últimos anos, as crises nos sistemas de produção decorrentes das práticas e escolha de manejos produtivos inadequados, a generalização das preocupações relacionadas à questão ambiental, entre outros fatores, têm estimulado um movimento de mudanças nas formas de exploração do meio natural e de gestão do espaço nos estabelecimentos familiares, no sentido da complexificação dos sistemas produtivos.

Neste artigo, procura-se compreender as mudanças que estão ocorrendo nos sistemas de produção familiares, principalmente considerando os processos de diversificação. Busca-se também discutir como as estratégias desenvolvidas atualmente pelos agricultores familiares refletem mudanças nas suas relações com a natureza e com o espaço, no sentido de garantir a permanência na terra, demonstrando um processo de certa estabilização da agricultura familiar regional.

Para fazer essa discussão, optou-se por partir do processo de surgimento da agricultura moderna e das mudanças nas visões de natureza como forma de situar os caminhos que as relações sociedade-natureza tomaram ao longo desse período e, a partir disso, estabelecer posteriormente relações com as atuais formas de exploração do meio natural e de agricultura desenvolvidas na Amazônia Oriental. Na segunda parte, observa-se brevemente como esse processo de modernização foi introduzido na Amazônia e como influenciou os padrões de exploração adotados na região e, em especial, na fronteira do sudeste paraense. E, na terceira parte, procura-se mostrar as iniciativas de diversificação dos sistemas de produção que estão sendo conduzidas pelos agricultores familiares do sudeste paraense como expressão da busca do estabelecimento de uma nova relação com a natureza.

\section{UM RÁPIDO OLHAR SOBRE OS CAMINHOS DA AGRICULTURA E DAS RELAÇÕES SOCIEDADE-NATUREZA}

\subsection{A agricultura moderna e o pacto contra o natural}

Entre as várias entradas possíveis, a discussão sobre os efeitos da ação humana sobre o ambiente tem nos caminhos tomados pela agricultura ao longo 
do tempo um viés interessante, principalmente considerando que as formas como as sociedades escolhem desenvolver essa atividade são determinantes na definição do grau e da intensidade de exploração e degradação da natureza.

Esse debate não é necessariamente novo. Já no século XVIII os reflexos das importantes transformações ocorridas no século anterior relacionadas ao surgimento do cartesianismo e ao início do movimento de modernização das sociedades ocidentais começaram a despertar interesse sobre as relações travadas entre sociedade e natureza. Em contraposição às concepções de mundo predominantes na pré-modernidade e Antiguidade e ainda na Idade Média, que percebiam o homem incluído na natureza, o paradigma cartesiano gerou mudanças profundas na forma do homem ver o mundo e de se relacionar com a natureza. Descartes baseou sua concepção na disjunção fundamental e definitiva entre esses duas zonas ontológicas (CAPRA, 2002; MORIN, 2003), influenciando na formação de uma visão antropocêntrica que coloca o bem-estar das pessoas como principal prioridade e delega à natureza uma posição secundária na hierarquia das preocupações humanas (FERRY, 2009).

Baseado na industrialização, cujo desenvolvimento teceu ligações bastante estreitas com o progresso técnico, o fenômeno da modernidade alterou a organização da produção, as relações sociais e as relações com o meio natural (BRANDENBURG, 1996). Nesse modelo de desenvolvimento urbano-industrial, que se tornou hegemônico mundialmente, a natureza assumiu uma condição de estoque de recursos naturais a ser utilizado ao bel-prazer do sistema para alimentar o aumento constante do volume da produção de bens materiais. Os riscos e barreiras que a natureza impunha passaram a ser algo que devia ser controlado e vencido por meio do uso de instrumentos técnico-científicos produzidos com ajuda da ciência.

Segundo Veiga (1991) e Ehlers (1999), pode-se dizer que um dos primeiros movimentos de transição em direção ao estabelecimento da agricultura moderna foi a eliminação progressiva do uso de "pousio" e a passagem para o cultivo anual das áreas. O desenvolvimento da produção industrial e a crescente demanda por matéria-prima animal e vegetal e o aumento da população e da demanda de alimentos exigiam aumento nas escalas e intensidades de produção e nos níveis de produtividade. Com o desaparecimento dos sistemas de "pousio" e com aumento da demanda por produtos agrícolas, a preocupação com a fertilização dos solos tornou-se prioridade.

O processo de transformação da agricultura para atender essas novas necessidades se deu a partir dos séculos XVIII e XIX em várias regiões da Europa. O marco foi a aproximação das atividades agrícola e pecuária, ou seja, de 
historicamente opostas, passaram a uma condição de estreitamente complementar ${ }^{1}$ com a adoção de um novo sistema de rotação de cultivos denominado de Norfolk. Esse período ficou conhecido como a Primeira Revolução Agrícola. Principal vetor de mudança, esse sistema possibilitou o aumento da produtividade na medida em que se baseava em uma combinação ecológica relativamente equilibrada, aproveitando ao máximo as complementaridades e simbioses naturais entre as espécies animais e vegetais envolvidas no sistema para garantir a fertilidade dos solos (ROMEIRO, 1998).

Com a consolidação da Revolução Industrial, no final do século XIX e início do século XX, outra grande mudança vai influenciar no processo de modernização da agricultura, principalmente na Europa e Estados Unidos. Apesar das vantagens que oferecia em termos agronômicos, o sistema Norfolk apresentava limitações para o desenvolvimento de uma agricultura de grande escala: uma era a grande quantidade de mão de obra e de tempo desprendido para a realização da fertilização orgânica e outra era restrição de expansão ou de ocupação exclusiva da terra por cultivos considerados mais rentáveis, como os grãos, devido à necessidade de utilização de área para o cultivo de forrageiras para a manutenção dos animais (EHLERS, 1999).

Os avanços tecnológicos nas indústrias de fertilizantes químicos, de rações, de sementes e de defensivos e o desenvolvimento da indústria de máquinas e implementos agrícolas foram determinantes no esforço de superar essas e outras limitações, possibilitando o gradativo abandono dos sistemas rotacionais e desvinculação da produção animal e produção vegetal, além de um aumento ainda maior das produtividades. Foi o período conhecido como a Segunda Revolução Agrícola.

Segundo Romeiro (1998), o eixo central dessa Segunda Revolução era tornar viável, através do progresso técnico, alicerce da modernidade, a prática do monocultivo. Com esse tipo de sistema de produção seria possível aos agricultores aproveitarem efetivamente as oportunidades de mercado investindo nos cultivos de espécies mais rentáveis. A lógica comercial dos sistemas de monocultivos transformava a relação entre as atividades agrícola e pecuária: a complementaridade entre elas cedeu lugar a uma concorrência por espaço. Era o início de um processo de simplificação ecológica dos sistemas produtivos (e consequente aumento da vulnerabilidade e instabilidade desses sistemas), de simplificação na

1 A base principal do sistema que tratou de fundir as práticas agrícolas e a pecuária, chamado Norfolk, era a substituição do "pousio" pela rotação de cultivos com plantas forrageiras leguminosas. Os diferentes métodos de rotação dos cultivos permitiram aumentar a lotação animal nas propriedades, afetando diretamente o processo de fertilização dos solos; e aumentar a diversidade de cultivos (ROMEIRO, 1998; EHLERS, 1999). 
organização do trabalho, de aumento do emprego de insumos industriais químicos e de consolidação de uma nova agricultura altamente consumidora de energia (EHLERS, 1999).

Nesse contexto, a agricultura assume um papel funcional e secundário ao setor industrial como fornecedora de matérias-primas e de força de trabalho e como consumidora de bens industriais (ALMEIDA, 1998, p. 39) (Figura 1).

Figura 1. Transformações ocorridas entre a Primeira e a Segunda Revolução Agrícola.

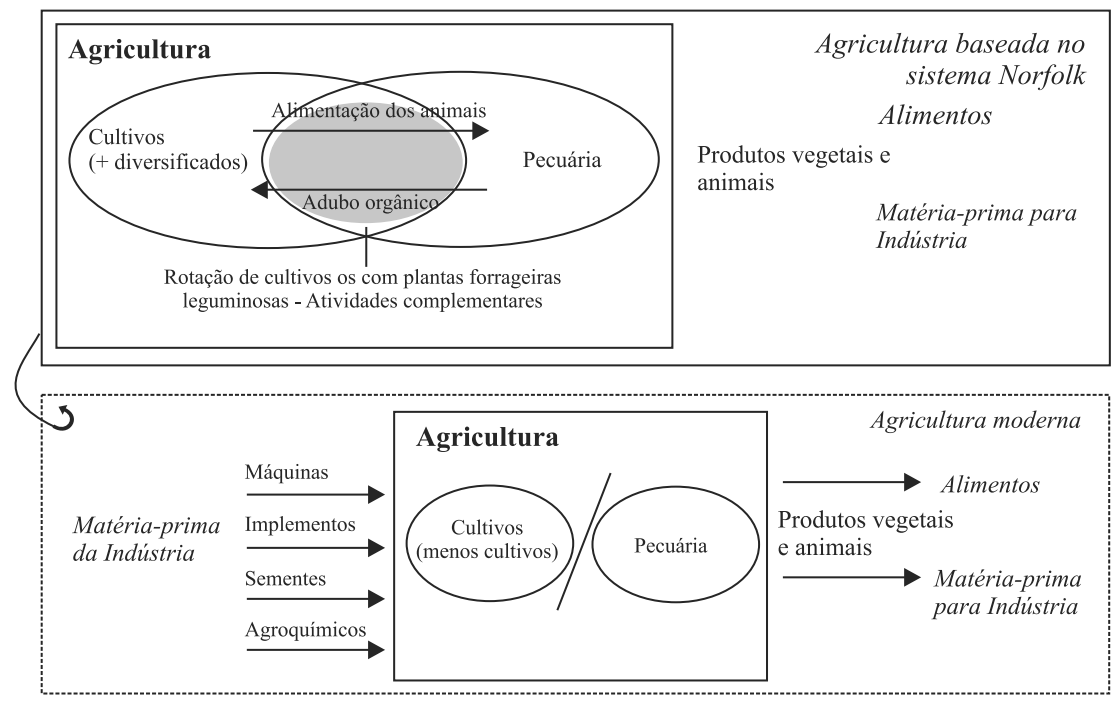

Fonte: Adaptado de Oliveira Jr. (1989).

Essas mudanças tecnólogicas trouxeram a indústria definitivamente para dentro da agricultura, diminuindo de forma drástica a sua dependência dos recursos e processos naturais. Há, nesse sentido, um movimento que Goodman, Sorj e Wilkinson (1990) chamaram de apropriacionismo, ou seja, um movimento de apropriação industrial de frações do processo de produção agrícola no intuito de superar as restrições ambientais. Era a expressão das tentativas de dominação e de "libertação" do homem da dependência da natureza.

O novo padrão, chamado agricultura convencional, clássica ou moderna, foi levado ao paroxismo, principalmente a partir do final da década de 1960, com a Revolução Verde. A despeito dos resultados positivos obtidos em alguns países, no tocante ao aumento da produção de alimentos, a adoção dessa agricultura moderna significava também a adoção de um sistema extremamente agressivo 
ao meio natural ${ }^{2}$. A busca por melhorar suas condições de vida e satisfazer suas necessidades levou a sociedade moderna a tratar o meio natural como um obstáculo a ser ultrapassado, uma vez que atrapalhava o alcance de seus objetivos. A relação estabelecida com a natureza era de antagonismo.

O processo de modernização expressou de forma clara a concepção cartesiana de desvinculação do ser humano da natureza. A convicção dessa separação é que justificaria e permitiria a manipulação da natureza, uma vez que era considerada como "um conjunto de objetos passivos, suscetíveis de serem usados e transformados pelos seres humanos" (FLORIT, 2004, p. 102). Segundo ele, tal visão desconsiderou a complexidade e o caráter dinâmico e adaptativo dos seres vivos que compunham os ecossistemas submetidos à agricultura moderna. A natureza, ao contrário, foi concebida como algo estático, que na medida em que fosse simplificada atingiria os objetivos que lhes foram pré-definidos. Eram os humanos contra a natureza, tentando dominá-la, sobrepujá-la em favor de seus interesses.

\subsection{A busca de reconexão com a natureza}

Após a II Guerra Mundial, ao mesmo tempo em que esse processo de modernização moldado sob uma lógica produtivista, tecnicista, consumista (de energia e bens e serviços) e altamente degradadora dos elementos naturais tornou-se a base dominante da civilização ocidental, os limites desse padrão de desenvolvimento também começaram a ser percebidos adquirindo dimensões mundiais mediante os elevados níveis de poluição e de degradação do meio natural. Os desequilíbrios ecológicos causados pelas técnicas, especialmente nas regiões tropicais, tornaram-se cada vez mais evidentes à opinião pública (ROMEIRO, 1998).

Com o processo de sensibilização ecológica, disseminado a partir do final dos anos 1960, aumentaram substancialmente as críticas contra o modelo ocidental de sociedade e contra os processos "potencialmente destrutivos" dele decorrentes, assim como proliferaram as denúncias de indiferença dessa sociedade em relação ao ambiente e as reivindicações de mudanças nas atitudes humanas em favor de uma relação menos desarmônica entre ambos (McCORMICK, 1992). Segundo Almeida (1999, p. 63), a questão que se colocava era como sair da sociedade do mais para aquela do melhor.

\footnotetext{
2 Muitos dos progressos gerados pelas inovações tecnológicas no processo de modernização ligadas à agricultura só puderam ser obtidas às custas da erosão e perda da fertilidade das terras, do esgotamento e contaminação dos lençóis freáticos, da dilapidação do patrimônio genético e da biodiversidade, além de outros efeitos negativos.
} 
$\mathrm{Na}$ esteira dos debates mundiais ${ }^{3}$, a insustentabilidade do modelo convencional de agricultura era um dos principais alvos de críticas. Os efeitos de ordem social (desigualdades, empobrecimento, exclusão), econômica (dependência das indústrias a montante e a jusante da produção, encarecimento dos custos de produção, queda dos níveis de renda) e, principalmente, de ordem ecológica (dilapidação da biodiversidade, erosão e degradação dos solos, poluição e esgotamento de recursos naturais não renováveis) criados por esse modelo e a compreensão da finitude dos recursos naturais serviram de estímulo para a emergência de manifestações na direção de uma agricultura mais sustentável, menos agressiva ao ambiente (ALMEIDA, 1998).

Não alheia ao discurso ecológico e à discussão de sustentabilidade, a agricultura convencional procurou encontrar maneiras de atender parcialmente às inquietações ambientais pelas quais era alvo de crítica. Sem se desconectar do paradigma técnico-produtivista, essa agricultura intensiva buscou soluções para a minimização dos problemas no desenvolvimento e uso de inovações tecnológicas que procurassem continuar garantindo as demandas do mercado, mas que também garantissem a qualidade do ambiente (KITAMURA, 2003). Em outras palavras, optou-se pela sofisticação do modelo, investindo, por exemplo, na produção de variedades de plantas mais resistentes a pragas e doenças, no sistema de plantio direto, na fixação biológica de nitrogênio, no sistema integrado de pragas, na produção de organismos geneticamente modificados (OGMs) ou transgênicos, sendo o foco dessas inovações a redução ou eliminação do uso de agrotóxicos na agricultura. Como se referem Caporal e Costabeber (2004), essas iniciativas seriam muito mais uma "Intensificação Verde" ou uma "recauchutagem do modelo da Revolução Verde", do que realmente uma mudança de princípios.

A principal manifestação de transformações na agricultura ocorreu, de fato, com a emergência de formas alternativas calcadas sobre matrizes paradigmáticas mais integradoras entre sociedade e natureza. Apesar de várias experiências em desenvolver outros tipos de agricultura se remeterem às primeiras décadas do século XX (algumas até antes disso), foi nos anos 1970 que elas se destacaram mais significativamente.

Agregadas sob um mesmo guarda-chuva de "agricultura alternativa", esse conjunto de vertentes que brotou em oposição ao padrão produtivo convencional se propunha a quebrar com esse modelo a partir de tecnologias e

3 Várias iniciativas de tratar os problemas ambientais foram levadas a cabo com o objetivo de encontrar soluções eficazes para a crise. A fundação do Clube de Roma (em 1968), a Conferência da Biosfera (em 1968), a Conferência de Estocolmo (em 1972), a elaboração do relatório Brundtland (1987) e a Rio-92 são algumas dessas iniciativas que marcaram essa busca de um novo modelo de desenvolvimento. 
práticas alternativas. De acordo com Almeida (1999), nesse tipo de agricultura a tecnologia, os processos e métodos de produção possuem um lugar importante, assim como se destaca a ideia de "autonomia" e "autoconstrução", já que cabe ao próprio agricultor definir seus sistemas técnicos (com uma harmonia maior entre seus componentes), de acordo com suas necessidades e a disponibilidade de "recursos" naturais.

Apesar de se diferenciarem nos procedimentos e princípios técnicos de produção e de se basearem em diferentes ideias de natureza - que distinguiam diferentes traços principais a serem respeitados para uma produção mais harmoniosa -, essas vertentes alternativas compartilham não só do objetivo de desenvolver uma agricultura mais sustentável, mas principalmente da oposição à visão mecanicista que está no cerne da atitude humana de controle da natureza ${ }^{4}$ (FLORIT, 2004).

Os tipos alternativos de agricultura procuram estabelecer uma relação diferente com a natureza. São os humanos buscando uma reaproximação, uma reconexão com a natureza. Partindo do princípio de que melhor seria os humanos respeitarem, acompanharem, "seguirem a natureza", essas proposições se fundamentam em uma concepção mais holística da natureza e procuram resgatar noções importantes como as de complexidade e dinamismo dos agroecossistemas, valorizando suas capacidades adaptativas e regenerativas e a diversidade de seus elementos (FLORIT, 2004).

No bojo desse entendimento de que o mundo é complexo e que a simplificação dos sistemas provoca desequilíbrios e desestabilizações ecológicas importantes, as agriculturas alternativas compreendem que é mais interessante manter a diversidade e multiplicidade de elementos e interações (típicas dos ecossistemas naturais) e levar em consideração os processos naturais, uma vez que produzem sistemas mais sustentáveis e menos suscetíveis às perturbações externas.

É nesse sentido que atualmente as iniciativas de mudanças nas formas de fazer agricultura têm enveredado por um caminho de estímulo à consolidação de sistemas produtivos que pautem pela diversificação, integração e sinergias das atividades (ALTIERI; NICHOLLS, 2003). Para Altieri (2002), essa busca pela diversificação dos sistemas agrícolas está na base do processo de estabelecimento de uma agricultura mais duradoura, mais harmoniosa com a natureza.

4 Para maiores detalhes sobre as diferentes vertentes alternativas de agricultura, ver Ehlers (1999) e Almeida (1999). Sobre as difentes ideias de natureza que as embasam, ver Florit (2004). 


\section{NATUREZA SELVAGEM X NATUREZA TRANSFORMADA: A LÓGICA MODERNA NA AMAZÔNIA}

Esse caminho das relações sociedade-natureza, ilustrado pelo surgimento da agricultura moderna, até a proliferação de tipos alternativos de agricultura baseados em relações mais harmoniosas com o ambiente, também foi percorrido no Brasil. De diferentes formas e em diferentes intensidades, as diversas regiões do país passaram por esse processo de modernização da agricultura e sofreram as consequências dele decorrentes.

Na Amazônia, essa concepção moderna clássica, baseada na oposição entre sociedade e natureza, mesmo tendo sido observada desde a época da colonização, vai ser definitivamente incorporada na região a partir do período de implementação das políticas de desenvolvimento do governo militar, na década de 1960, passando a fundamentar os processos de ocupação e exploração do meio natural aí desencadeados.

O paradigma racionalista e antropocêntrico no qual se sustentava a percepção das elites nacionais sobre a região amazônica - vista como uma fronteira de recursos, na qual o capital poderia refazer seu ciclo de acumulação a partir dos novos estoques disponíveis - e o contexto político-econômico que colocava como meta principal promover o crescimento econômico do país foram determinantes na decisão do Estado atuar de forma mais incisiva na Amazônia (CASTRO, 2005). De acordo com Becker (2005), partindo da noção de progresso, esse crescimento era visto como algo linear e infinito e se baseava na incorporação de novas terras e recursos naturais, igualmente vistos como inesgotáveis. Além disso, a concepção moderna era evidente ao se considerar que havia necessidade de transformar a natureza bruta amazônica em uma natureza dominada e geradora de produtos capazes de serem absorvidos pelo mercado.

Essa ideia de que a incorporação da Amazônia ao espaço nacional passaria obrigatoriamente pela transformação de sua natureza selvagem já se fazia presente desde o início da colonização da região. Apesar da importância que o extrativismo adquiriu na economia amazônica, ele nunca foi visto com bons olhos por boa parte da sociedade e nem pela igreja: a visão dominante da época atribuía a esta atividade um caráter não civilizatório na medida em que não incluía processos de transformação da natureza, compreendida como o espaço do mal, lugar de desordem, lugar ausente de Deus. Daí o imperativo de que para tornar esse espaço uma obra civilizada e cristã, a natureza fosse modificada pelo trabalho humano (COSTA, 1992; PÁDUA, 2004). 
Tal visão baseada na oposição entre natureza bruta $\mathrm{x}$ natureza transformada (pelos humanos), barbárie x civilização vai ser recorrente ao longo da ocupação da Amazônia. O desejo de que a agricultura - enquanto símbolo dessa natureza transformada - viesse a ser a principal atividade econômica da região já vinha orientando várias políticas governamentais desde o século XVIII, mas vai ser no período do regime militar que esse intuito ganhará impulsos significativos (COSTA, 1992).

O projeto de modernização nacional da ditadura militar com vistas à rápida inserção do Brasil na ordem mundial da época vai estimular o interesse do Estado pela Amazônia e vai ser o principal eixo orientador das políticas para a região. A agricultura fazia parte desse projeto e a expansão da fronteira agrícola amazônica se inseria no contexto como componente importante na redistribuição territorial da mão de obra excedente de outras regiões do país e no processo de expansão do capital (COSTA, 2000).

Segundo esse autor, para a ditadura, o sucesso desse projeto na fronteira amazônica passava por um desenvolvimento agrícola promovido a partir do incentivo à empresa capitalista moderna ao invés da agricultura familiar, criando um fator diferenciador entre esta e as demais fronteiras agrícolas do país. O "bloqueio" à agricultura familiar se fazia necessário porque, de certo modo, pela forma como desenvolvia a agricultura, atrapalhava a modernização da agricultura na região, à medida que restringia a expansão do mercado da indústria de insumos agrícolas (indústrias de tratores, adubos químicos, sementes, herbicidas etc.).

Nesse sentido, o Estado procurou implementar ações fundamentais que pudessem viabilizar as condições materiais e jurídico-administrativas necessárias para atrair grandes empreendimentos nacionais e internacionais para a região, dispostos a explorar o espaço segundo uma lógica estritamente capitalista. A criação da SUDAM, do BASA, a implantação das redes de integração espacial, a concessão de subsídios, a centralização da pesquisa agropecuária e da extensão rural no estímulo à adaptação e adoção dos pacotes tecnológicos da Revolução Verde faziam parte dessa viabilização das condições à modernização da agricultura.

De maneira concreta, esse processo de estabelecimento de uma agricultura moderna na Amazônia, e em especial nas áreas de fronteira, materializou-se a partir dos incentivos fiscais e creditícios concedidos a grandes proprietários e investidores para o estabelecimento da atividade de pecuária extensiva. O investimento nessa atividade se propunha a modificar o quadro de "isolamento e vazio" que se atribuía à região na época, uma vez que o modelo de uso da terra estimulado se baseava na substituição da floresta por pastagens cultivadas, dentro de uma concepção do Estado de que terra em pasto era considerada produtiva e valorizada. 
Apesar da forte ação governamental com foco sobre os grandes empreendimentos agropecuários capitalistas, a agricultura familiar não deixou de se desenvolver e de se tornar um importante ator da agricultura regional. $\mathrm{O}$ intenso movimento migratório desencadeado nessa época foi responsável por atrair um considerável contingente populacional. Motivados pelos programas oficiais de colonização ou a partir de movimentos "espontâneos" de migração (não coordenados pelo Estado), inúmeros camponeses e trabalhadores oriundos de outras regiões do país, principalmente do Nordeste e do Centro-Sul, deslocaram-se em direção à Amazônia embalados pelo sonho de conseguir terra para plantar ou em busca de melhores oportunidades de trabalho em obras de infraestrutura ou nas atividades de exploração madeireira, garimpo, mineração ou pecuária (CASTRO, 2004). Sempre é bom lembrar que o fluxo migratório nesta região se orientou mais pelas frentes de trabalho (grandes projetos de infraestrutura) e não por programas de incorporação destes contingentes em investimentos agropecuários.

Por se tratarem de migrantes, originários de outras regiões do país, com características diferentes, essas famílias não tinham experiência em lidar com o meio natural amazônico. O desconhecimento do valor de uso dos produtos da floresta, na maioria das vezes, reduzia o papel da mesma exclusivamente ao de reserva de nutrientes para a produção de roças. A relação estabelecida com o meio natural era, de certa forma, utilitarista, na medida em que o viam principalmente como fonte de recursos para o desenvolvimento das atividades produtivas que garantiam a subsistência e uso da família (extrativismo, agricultura, matérias-primas para construções, carvão etc.).

Diante desse afluxo intenso de pessoas de fora da Amazônia, a diversidade de atores sociais e de interesses em relação à apropriação do meio natural e as mudanças na infraestrutura vão contribuir para imprimir um pesado e veloz processo de exploração do meio natural e transformação da paisagem nas fronteiras amazônicas (e a paisagem modificada significava a entrada na modernidade). $\mathrm{Na}$ fronteira do sudeste do Pará, em especial, os impactos foram maiores, uma vez que esse espaço foi alvo de vários dos grandes projetos previstos para a Amazônia (de estruturas de acesso e comunicação, de geração de energia, de exploração mineral) e que Marabá se transformou no principal centro de referência regional.

Tal facilidade de conexão com o restante do país, aliada à abundância de "recursos" naturais e aos incentivos do governo, transformou o sudeste paraense em um espaço atraente aos olhos de diferentes tipos de atores, com intenções diferenciadas de uso da natureza. Esse conflito de interesses pelo uso dos recursos naturais, dentro de uma estrutura fundiária com um modelo concentrador, contribuiu para a criação de um ambiente de disputa pela terra (enquanto principal 
meio de produção) com repercussões significativas sobre o padrão de exploração do meio natural: o desmatamento, além de parte da opção técnica de transformação do espaço selvagem em moderno através da agricultura - moderno no sentido de modificado pelo homem -, também era utilizado com uma forma de legitimação da posse da terra, na medida em que expressava a aplicação de trabalho na terra.

Foi em decorrência desses fatores ligados à questão fundiária, mas também em função da consolidação do discurso do Estado que incentivava a pecuária extensiva e vinculava o "beneficiamento" da terra à modernidade que o padrão de exploração do meio natural baseado na implantação de pastagens tornouse extremamente predominante nas áreas de fronteira, tais como a do sudeste paraense. Nos moldes dos princípios da agricultura moderna, essa forma de utilização do solo era baseada na simplificação dos sistemas de produção em monocultivos de pastagens ${ }^{5}$, voltado exclusivamente para o desenvolvimento da atividade de pecuária de corte.

Esse padrão de exploração era amplamente utilizado pelos grandes proprietários, com objetivos produtivos ou especulativos. Mas, não só por eles. Nas condições bastante precárias do meio socioeconômico e nas incertezas quanto à posse da terra que caracterizavam as áreas de fronteira entre as décadas de 1980 e 1990, no sudeste do Pará também os agricultores familiares adotavam o mesmo padrão, porém com motivações bem diferentes. O interesse na implantação de pastagens e na criação de gado estava no fato de acreditar que essa atividade podia lhe possibilitar a entrada em um processo de capitalização capaz de oferecer melhores condições de investimento e de vida. A exploração do estabelecimento seguindo essa lógica produtiva, em geral, levava-o a uma condição de crise, uma vez que, com a baixa capacidade de investimento dos agricultores para cobrir as exigências de capital e trabalho para recuperá-las, a formação de pastos significava a inutilização das áreas para o cultivo da roça, principal atividade que garantia a subsistência da família. Em outras palavras, a implantação das pastagens subentendia rumar para a simplificação do sistema de produção, para uma perigosa especialização na pecuária, mesmo que a princípio não fosse esse o projeto dos agricultores.

Nesse contexto, os agricultores da fronteira agrícola do sudeste do Pará acabaram estabelecendo uma relação de certa forma paradoxal com o meio natural, principalmente com a mata: ao mesmo tempo em que precisavam e dependiam das áreas de floresta para a formação de roças, não hesitavam em retirá-la até seu completo esgotamento. Essa aparente contradição podia ser explicada, pelo menos

5 Mesmo sabendo que, por vezes, essas pastagens eram formadas por mais de uma espécie, considera-se como monocultivos, no sentido de que estava relacionada a uma única atividade. 
em parte, pelas estratégias mais gerais de reprodução social da família e de seu modo de vida relacionadas à questão da terra e da busca de melhores condições de vida. Como essas estratégias não necessariamente passavam pela permanência no mesmo lugar, sendo comum, na época, nessa área de fronteira, a venda da terra "beneficiada" em pasto e o deslocamento para novas áreas de floresta para reinício do processo, as relações que os agricultores estabeleciam com o meio natural se definiam prioritariamente pela garantia da reprodução social da família e não pela preservação do mesmo.

Apesar de todo o esforço do governo em promover a agricultura moderna na Amazônia, é preciso dizer que o processo de introdução dos padrões da Revolução Verde na agricultura ou na pecuária não ocorreu da mesma forma que em outras regiões do país. Na fronteira do sudeste paraense, por exemplo, não houve nas primeiras décadas de ocupação da fronteira uma absorção significativa da utilização de insumos e maquinários no processo produtivo, prevalecendo muitas das práticas tradicionalmente utilizadas como, por exemplo, o uso do corte-queima ou do pousio. Mesmo nos grandes empreendimentos agropecuários, a utilização de tecnologias modernas não se deu na intensidade esperada, sendo em boa parte das fazendas a pecuária desenvolvida sem seguir necessariamente as recomendações técnicas. Também em termos de produtividade e resultados econômicos, os ganhos ficaram muito aquém dos esperados.

No entanto, a despeito disso, não se pode negar que a lógica industrial da sociedade moderna conseguiu penetrar na região e definir os tipos de relações estabelecidas entre sociedade e natureza. Ela está presente também na exploração madeireira ou na mineração, na medida em que a floresta e minérios são encarados como recursos infinitos que estão à disposição para serem utilizados pelas pessoas para satisfação de suas necessidades. Mas, o mais interessante é que a presença dessa lógica tem se expressado hoje, justamente pela proliferação do uso de agrotóxicos, adubos químicos industrializados, mecanização e pela expansão das áreas de monocultivos (principalmente de eucaliptos). Ou seja, por elementos que na época do início do processo de modernização da agricultura na Amazônia, e em particular da fronteira sudeste do Pará, não apareciam de forma significativa, mas que atualmente vêm sendo utilizados com mais frequência tanto por grandes proprietários quanto por agricultores familiares. 


\section{A BUSCA PELA DIVERSIFICAÇÃO: NOVAS RELAÇÕES ENTRE SOCIEDADE E NATUREZA NA AMAZÔNIA?}

Apesar de elementos característicos da agricultura moderna encontrarem hoje em dia mais espaço nos sistemas de produção amazônicos, por outro lado, também têm sido observadas mudanças nas formas de exploração do meio natural. Nas últimas décadas, a ampliação e vulgarização do debate sobre a questão ambiental e a evidência dos efeitos sociais e ambientais que esse padrão de exploração do meio natural adotado em áreas como a fronteira do sudeste do Pará têm provocado uma intensificação das críticas da sociedade nacional e internacional sobre seu caráter predatório e sobre a necessidade de promover mudanças nas relações estabelecidas com o meio natural.

As iniciativas nesse sentido, de diminuir os efeitos negativos sobre o ambiente, têm sido inúmeras e vêm de várias direções. O Estado tem agido através de certas mudanças na legislação ambiental e através da implementação de políticas públicas nos campos agrário, agrícola e ambiental que visem coibir direta ou indiretamente a exploração predatória do meio natural ${ }^{6}$. A partir da década de 1990, o foco mudou e a agricultura familiar passou a receber maior atenção, sendo através dela que o estado tem procurado estimular a introdução de novas lógicas de exploração a partir de alternativas produtivas, no sentido da diversificação e da perspectiva de uma agricultura mais sustentável.

Os órgãos financiadores internacionais também têm procurado contribuir, exigindo a inclusão do componente ambiental e da sustentabilidade das ações em suas diferentes dimensões (ambiental, social, econômica) nos projetos submetidos a financiamento. Igualmente, as organizações não governamentais têm incentivado a reflexão sobre a questão ambiental, desenvolvendo ações direcionadas à busca de alternativas a modelos predatórios de exploração. E, pelo lado das organizações e representações ligadas aos agricultores, há a adoção de um novo discurso que incorpora a problemática ambiental e há também um esforço em apoiar ações que procurem estimular as iniciativas de diversificação dos sistemas produtivos em estabelecimentos familiares.

Além disso, internamente aos estabelecimentos agrícolas, as formas de exploração adotadas no passado baseadas na simplificação dos sistemas de

É certo que a ação do Estado em relação à questão ambiental apresenta contradições. As discussões nas alterações no Código Florestal para atender as reivindicações da bancada ruralista e os incentivos ao agronegócio, a pressão para implementação dos projetos estruturantes do PAC, a despeito dos potenciais impactos ambientais que causarão são exemplos dessas contradições. No entanto, interessa destacar que também há esforços em desenvolver ações de proteção ao ambiente. 
produção e, na grande maioria das vezes, na ausência de uso de práticas de manejo adequadas acabaram levando os estabelecimentos a situações de crise para a materialização da produção, em função de limitações ecológicas (escassez de vegetação, queda da fertilidade dos solos, processos de erosão, escassez de água). Essas condições, de certa maneira têm "empurrado" os agricultores a promoverem mudanças em suas estratégias produtivas, buscando na diversificação uma alternativa para garantirem a reprodução social da família (OLIVEIRA, 2009).

Independentemente de onde venham os estímulos, o fato importante a destacar é que atualmente diversas noções de desenvolvimento e sustentabilidade têm sido introduzidas e estimuladas com muito mais frequência nos debates, discursos e ações implementadas na região.

Nesse contexto de busca pela consolidação de uma agricultura mais sustentável, a diversificação dos sistemas de produção tem se constituído no carro-chefe das iniciativas de mudanças. Praticado historicamente por populações tradicionais, esse tipo de agricultura, baseado na diversificação e em sistemas mais complexos, não é algo necessariamente novo na Amazônia. Mesmo nas áreas de fronteira agrícola, onde o processo de simplificação dos sistemas foi mais incisivo, sistemas de produção diversificados já tinham lugar, sendo, porém, muitas vezes "sombreados" pela forma predominante de exploração voltada para a implantação de monocultivos de pastagens e manejo extensivo da pecuária de corte, para fins de exportação pecuária ${ }^{7}$.

No Pará, em áreas de fronteira centenárias, como a do nordeste paraense, essas mudanças da forma de fazer agricultura na direção da diversificação dos sistemas produtivos tiveram início já há aproximadamente três décadas (CARVALHO, 1998; HURTIENNE, 1999; COSTA et al., 2000). No entanto, em áreas de fronteira mais recentes, como no sudeste, tais mudanças começam a tomar maiores dimensões com a intensificação das crises de sustentabilidade dos sistemas de produção e das dificuldades em manter a subsistência e reprodução social da família.

Centrando-se no caso do sudeste paraense, para ilustrar esse processo de complexificação dos sistemas produtivos familiares, constata-se que, seja por causa das exigências da política ambiental e/ou dos incentivos da política de crédito e da

\footnotetext{
Essa presença de sistemas diversificados é mencionada em estudos realizados na região do sudeste paraense, por exemplo, como o de Reynal (1999). No entanto, aparentemente, é tratada muito mais como fazendo parte dos momentos iniciais (ou até um pouco mais) de um processo de evolução dos estabelecimentos que, em geral, "termina” na especialização na pecuária e não como parte de um projeto da família a longo prazo. Evidentemente, essa leitura está vinculada a um dado contexto, em uma determinanda época, mas não enfatiza as iniciativas que não necessariamente seguiram esse caminho de evolução.
} 
assistência técnica baseados no discurso da sustentabilidade, seja pelas necessidades imperativas dos agricultores em encontrar saídas para lidar com a crise e diversificar as fontes de renda, está ocorrendo um importante movimento de introdução de novas atividades produtivas ou de redefinições nos papéis desempenhados pelos componentes já existentes no sistema de produção.

Nesse contexto de mudanças, Oliveira (2009) observou iniciativas de diversificação envolvendo diferentes tipos de atividades produtivas. Ela pode materializar-se desde a simples valorização de atividades já desenvolvidas no estabelecimento, como no caso dos porcos e aves (aumentando o plantel e/ou melhorando o manejo), até a introdução de novos tipos de atividades. Nesse último caso, merece destaque a introdução de criações como a caprinocultura, ovinocultura, apicultura e, principalmente, a piscicultura, que tem canalizado o maior interesse dos agricultores, e a incorporação de cultivos permanentes com espécies frutíferas (cupuaçu, maracujá, cacau, banana, açaí, por exemplo) ou florestais (mogno, teca, andiroba, entre outras), a partir de cultivos solteiros ou de sistemas agroflorestais. Além dessas, Martins e Oliveira (2010) mencionam também a introdução dos cultivos de hortas nos sistemas de produção familiares, desenvolvidos a partir de iniciativas individuais ou coletivas; para alguns agricultores, principalmente aqueles com estabelecimentos localizados próximos a centros urbanos, essa atividade tem despertado tanto interesse a ponto de adotarem estratégias específicas para o uso de áreas que consideram mais propícias (utilização de ilhas ou áreas de vazante, por exemplo), sejam elas dentro ou fora do estabelecimento ou da localidade.

Muitas dessas atividades introduzidas ou revalorizadas não necessariamente são feitas com espécies animais e vegetais nativas. Somente para dar um exemplo, a apicultura e piscicultura são desenvolvidas utilizando espécies exóticas, como tilápia e abelha africana, assim como são exóticas várias espécies vegetais utilizadas na implantação de cultivos permanentes, como a teca, eucalipto e algumas olerícolas.

Nas áreas onde os estabelecimentos ainda possuem reservas significativas de floresta primária, a diversificação dos sistemas produtivos pode incluir a exploração de espécies nativas, tais como a castanha-do-pará, o cupuaçu e o açaí nativos, a andiroba e copaíba (produtoras de óleos), ou mesmo a extração de matériasprimas (sementes, cipós, raízes, cascas etc.) para a fabricação de artesanato ou remédios, sendo esta uma forma de valorização da floresta e de seus componentes. A floresta passa, assim, a assumir um papel diferente daquele que durante anos lhe foi unicamente atribuído, de reserva de nutrientes para roça de corte-queima.

Também se pode considerar que esse processo de diversificação esteja ocorrendo a partir de uma reorientação do tipo de produto a ser valorizado em 
atividades já desenvolvidas. É o caso, por exemplo, da pecuária. Ela permanece como um componente importante dos sistemas de produção, porém, com um esforço dos agricultores em procurar uma forma de combiná-la com outras atividades produtivas, o que requer mudanças nas formas de gestão do espaço, na maneira de criar e no tipo de aptidão do rebanho. Isso tem sido observado nas tentativas de investir na produção leiteira - que com o desenvolvimento da rede viária e das estruturas de beneficiamento de produtos da pecuária (centrais de resfriamento e laticínios) ganhou maiores oportunidades de comercialização - e no interesse dos agricultores em mudar a aptidão da criação de pecuária de corte para mista ou leiteira, bem como nas iniciativas de restrição dos tamanhos dos rebanhos $^{8}$ e de adotar um manejo menos extensivo de criação (OLIVEIRA, 2009).

Nesse esforço de diversificação, a autora chama atenção ainda para a questão da roça. No processo de simplificação dos sistemas de produção sofrido por inúmeros estabelecimentos familiares na região do sudeste paraense e em outras regiões de fronteira, a roça gradativamente ia perdendo seu lugar para as pastagens e para a pecuária até sofrer uma diminuição drástica de sua diversidade, em termos de composição de espécies ou mesmo não ser mais praticada. No entanto, vários agricultores têm feito grandes esforços e lançado mão de diferentes estratégias para disporem de condições que garantam a manutenção do cultivo da roça (mesmo que menos diversificadas do que eram $)^{9}$ como componente do sistema de produção. Entre esses esforços, podem-se citar, principalmente, as mudanças na forma de uso do espaço, com a reutilização de áreas de pastagens para a formação de roças e a destinação de uma área específica para o cultivo da roça, podendo esta ter diferentes antecedentes, sejam mata, capoeira ou pasto.

No caso dessa estratégia de destinação de uma área exclusiva para roça no estabelecimento, foi observado, em alguns estabelecimentos, certa "itinerância" de uso do espaço circunscrito para essa atividade. Ou seja, há uma espécie de "rotação" de uso da área: dentro do espaço destinado ao cultivo da roça são estabelecidas divisões internas e, enquanto uma parte é utilizada, as outras são

8 No caso dos estabeelcimentos em áreas recentes de assentamento, isso está relacionado ao tamanho dos lotes, de 40 a 50 ha, e às limitações que a disponibilidade de área impõe para a prática da pecuária extensiva. Para os agricultores, não é possível viver exclusivamente da pecuária em um lote pequeno, dado não haver espaço para aumentar o rebanho até o nível que julgam suficiente para cobrir as necessidades da família. Incluir essa atividade enquanto componente de um sistema mais complexo, composto por outros vários componentes, é para muitos a principal alternativa para garantir a manutenção da família.

9 Tradicionalmente, as roças cultivadas pelos agricultores da região são compostas por mais de uma espécie. Em geral, englobam basicamente os cultivos de grãos, como arroz, milho e feijão ou fava, além da mandioca para fabricação de farinha. O mesmo espaço é ainda aproveitado para outros plantios de espécies de ciclo curto como jerimum, melancia, entre outros. 
mantidas em pousio. Mesmo sendo períodos de pousio extremamente curtos (em geral, inferiores a cinco anos), que não possibilitam produtividades elevadas, mostram um esforço de resgate dessa prática no interior do estabelecimento (MARTINS; OLIVEIRA, 2010).

O resgate de antigas práticas e a adoção de novas, a introdução de novas atividades e a revalorização de outras já desenvolvidas, a recuperação ou volta em áreas já exploradas para viabilizar as produções animal e vegetal, formam um conjunto de estratégias dos agricultores que fazem parte desse processo de mudança para diversificação (e de um processo maior de garantia da reprodução social) e que tem provocado alterações, entre outras coisas, na forma de exploração do meio natural, na gestão do espaço e na paisagem interna do estabelecimento, além de já começar a provocar também alterações na paisagem regional. A Figura 2 ilustra as mudanças nas formas de exploração do meio natural e a gestão do espaço ao nível de estabelecimento agrícola.

Figura 2. Esquema ilustrativo das mudanças nas formas de exploração do solo e de gestão do espaço do estabelecimento.

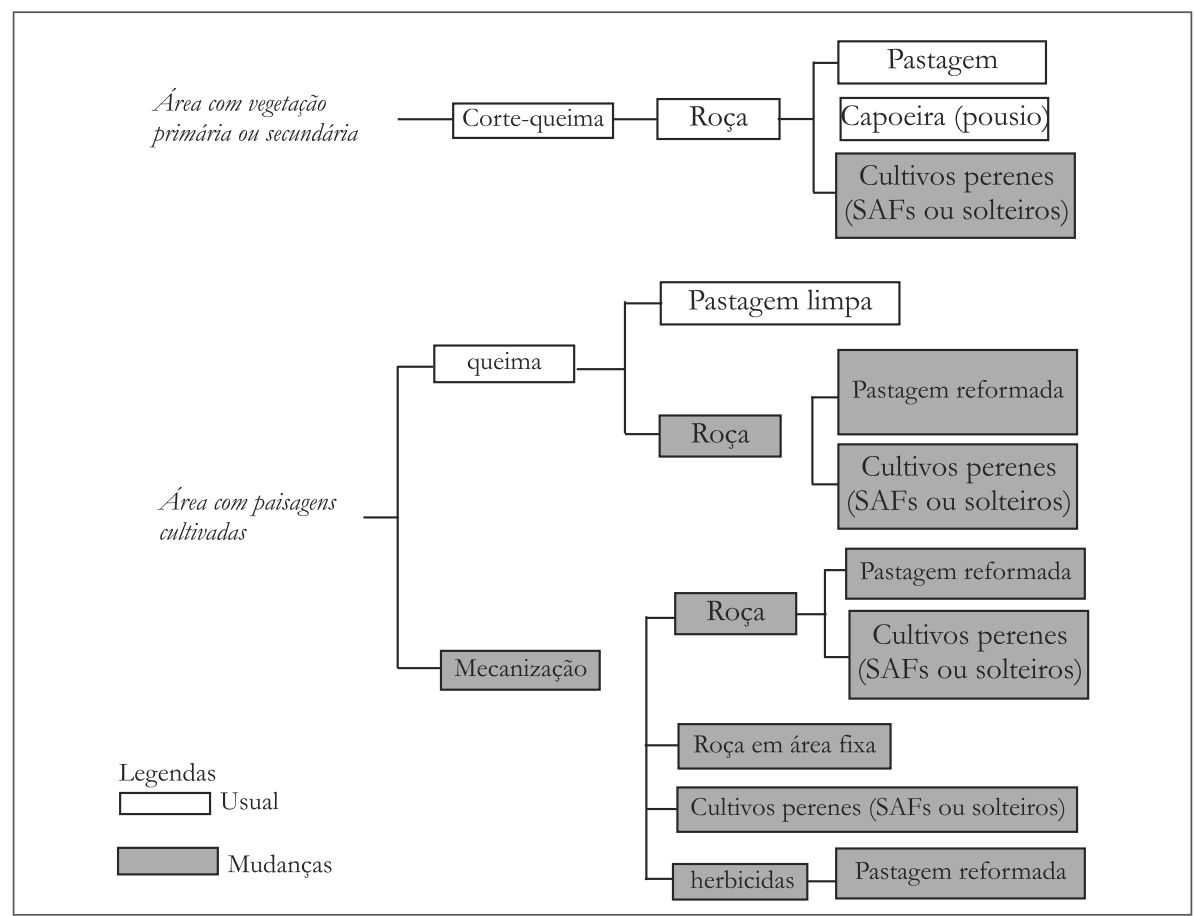

Fonte: Adaptado de Oliveira (2009). 
Essa decisão dos agricultores de promover a diversificação dos sistemas de produção está relacionada com a busca por aumentar as possibilidades de garantia da reprodução social da família, principalmente na sua dimensão material ${ }^{10}$. Conforme propõe Ellis (2000), ela pode ser interpretada como uma escolha ${ }^{11}$ pensada pelos agricultores dentro das alternativas e dos recursos existentes, com o propósito de diminuir as vulnerabilidades a que o estabelecimento está sujeito.

Tal escolha se insere dentro do que Ellis (1998; 2000) chamaria de estratégia de risco. Para esse autor, risco é entendido como a probabilidade subjetiva percebida pelos indivíduos e pelas suas famílias de ocorrer alguma frustração em uma (ou em mais de uma) das fontes de receitas e de autoconsumo, o que pode comprometer sua sobrevivência. As estratégias de risco corresponderiam, então, às iniciativas realizadas pelas famílias no sentido de aumentar o conjunto de alternativas de receitas do estabelecimento e conseguir uma margem maior de segurança. É dentro desse espírito de lidar com os riscos existentes atualmente que os agricultores dessa região têm buscado adotar essas estratégias de diversificação dos cultivos e das criações dentro dos seus sistemas de produção.

É importante dizer que várias dessas iniciativas de diversificação têm sido possíveis por meio do acesso ao crédito, mas há também casos de agricultores que têm procurado implantar essas atividades no estabelecimento por conta própria. Para isso, utilizam como suporte rendas provenientes da previdência rural, crédito consignado, ajuda de parentes, trabalhos não agrícolas ou extra-agrícolas. Como na maioria das vezes são experiências novas e requerem algum tipo de investimento inicial ou de manutenção, os agricultores preferem desenvolvê-las com recursos externos ou se tiverem fontes de renda que garantam a segurança financeira de modo a não colocar em risco a manutenção da família (OLIVEIRA, 2009).

Esse não é um processo isolado do sudeste paraense. Em outras fronteiras do estado com o mesmo tempo de ocupação, como no sul do Pará, esse processo de diversificação também está em curso, sendo até mais antigo (existe antes mesmo das atuais políticas de crédito). A presença de pecuária extensiva e de monocultivos de soja na região, levou os agricultores a perceberem e sentirem os efeitos negativos desse modelo industrial de agricultura, apesar de não terem entrado de forma significativa nesse modelo. Várias iniciativas de organizações não governamentais

10 Entende-se a reprodução social da família, conforme Raynaut (1994) e Barel (1973), como um processo global composto por subprocessos. Ambos destacam os subprocessos relacionados às dimensões material e social-cultural e Raynaut destaca ainda a dimensão demográfica.

11 Para Ellis (2000), a diversificação das atividades de uma unidade doméstica se dá a partir de escolhas, entendidas como ação voluntária e pró-ativa das famílias, ou a partir de necessidades, entendidas como a ação involuntária das famílias mediante problemas ou acontecimentos não esperados. 
nas décadas de 1980 e 1990 demonstraram o alto grau de interesse e investimento das famílias em sistemas de produção diversificados e com relativa autonomia.

Experiências que mantém elementos tradicionais dos sistemas de produção familiares (cultivos anuais, pequenos animais e quintais agroflorestais) incorporaram novos elementos que integram as demais atividades produtivas e aumentam a capacidade de regulação interna do sistema. Como exemplo, a introdução de sistemas agroflorestais (SAFs) e a apicultura têm promovido uma reconstrução dos sistemas de manejo, visto que estas atividades não toleram o uso do fogo, além de dependerem de um alto grau de biodiversidade existente desde o lote até a microrregião de influência. Diante destas mudanças estruturais e de gestão do lote, as organizações locais (associações, sindicatos e federações) têm sentido a necessidade de concepção de novos nichos de mercado (feira da agricultura familiar, abastecimento da merenda escolar etc.) no sentido de valorização e maior visibilidade da categoria (PINTO et al., 2010).

No sudeste paraense, o que chama a atenção nesse processo de diversificação é que se por um lado procura se constituir em uma alternativa ao princípio moderno da especialização, por outro, incorpora elementos da agricultura intensiva, na medida em que, muitas vezes aparece associado ao uso de insumos químicos industrializados e ao uso de mecanização para que seja viabilizado. As decisões de voltar em áreas de pastagens para explorar com lavouras, cultivos de espécies perenes frutíferas ou com sistemas agroflorestais, reformar áreas de pastos infestados com invasoras para possibilitar a manutenção de uma pecuária com rebanhos de tamanhos reduzidos ou investir em novos cultivos têm levado os agricultores a optarem pelo uso da mecanização (em baixo grau ainda), além do uso de herbicidas, inseticidas, adubos químicos e irrigação.

Esses movimentos contraditórios de "sair por um lado e entrar pelo outro" na lógica moderna pode encontrar alguma explicação no fato de que, diferentemente de como ocorreu em outros lugares, os agricultores familiares dessa região não foram estimulados a entrar no processo da modernização da agricultura, uma vez que, como já ressaltado anteriormente, este foi direcionado, na época, aos grandes proprietários. Em função disso, esses agricultores não viveram e sofreram com os problemas causados pela adoção desse tipo de agricultura e, por isso, não percebem de maneira evidente os efeitos negativos que pode causar.

De uma maneira geral, por ser uma região marcada por investimentos nos campos da pecuária extensiva e da siderurgia (e não na produção agrícola, as motivações em experimentar alternativas estão relacionadas muito mais a uma crise dos sistemas de produção que se explica pelo processo acelerado de supressão da biodiversidade, do que essencialmente pela adoção dos elementos da 
Revolução Verde. Por ser algo relativamente recente na região, as consequências em relação à saúde humana, à contaminação da água, à compactação dos solos etc., ainda não foram sentidas efetivamente e, por isso, não passaram a fazer parte das preocupações dos agricultores.

Além dessa falta de percepção das consequências negativas, essa utilização de insumos externos também está relacionada com uma estratégia dos agricultores em minimizar a necessidade de intensificação da aplicação de trabalho que, segundo Costa (1994) citado por Hurtienne (2005), geralmente é necessária para levar adiante o processo de introdução de inovações no sistema de produção: voltar nas áreas de pastagens para roças, por exemplo, requer maior esforço para tirar o capim e preparar o terreno e mais capinas para conter as invasoras, esforços estes que, na medida das possibilidades dos agricultores, são minimizados com o uso de mecanização e herbicidas ${ }^{12}$.

Mas, nem sempre essa minimização da intensidade de aplicação de trabalho é possível. Estudos realizados sobre mudanças nas estratégias produtivas mostram a necessidade de aumento do tempo de trabalho para garantir o desenvolvimento das mudanças inovativas: por exemplo, utilizar áreas para realizar roças ou hortas fora do estabelecimento ou da localidade requer maior tempo para deslocamento, assim como é necessária maior aplicação de tempo e trabalho para a realização de novos manejos (irrigação manual, retirada do leite, limpeza de açaizais, rotação de pastagens, cuidados com a horta etc.) ou outras práticas desenvolvidas manualmente (OLIVEIRA, 2009; MARTINS; OLIVEIRA, 2010).

Pode-se dizer, portanto, que no caso do processo de diversificação no sudeste paraense, há um aumento importante na aplicação de trabalho que garante as dinâmicas inovativas, mas há também, em alguns casos, um aumento na aplicação de capital.

Outra explicação possível ainda é que os sistemas de produção estão em meio a um processo de adaptação. O predomínio de trajetórias familiares de migração, aliado às inúmeras iniciativas de mudanças na estrutura e forma de funcionamento dos sistemas de produção ilustram a capacidade dos agricultores em elaborar respostas para criar e recriar as condições para garantirem a reprodução da sua família. Tais estratégias demonstram a maneira como as famílias estão

12 É importante destacar que, de maneira um pouco diferente do constatado por Carvalho (1999) no nordeste paraense, nessa fronteira do sudeste as dinâmicas inovativas de diversificação não possuem necessariamente uma relação inversa entre faixa etária e esforço de mudança. No sudeste paraense, muitos são os agricultores com mais idade, que buscam promover essas mudanças. Como dito anteriormente, o fato de disporem de aposentadorias e, consequentemente, de certa segurança de renda lhes coloca mais dispostos a promover mudanças porque acreditam que os riscos estão cobertos pelo benefício. 
procurando assimilar as perturbações pelas quais vêm passando, de como estão se recompondo e se adaptando às atuais condições disponíveis.

Nesse processo, a contradição é uma característica intrínseca do que Godelier chama de ciclo de adaptação-desadaptação. Ele apresenta alguns exemplos dessas contradições inerentes ao processo: a partir da análise do comportamento de certas sociedades, observou que mesmo que determinadas técnicas adotadas ou respostas desenvolvidas às limitações enfrentadas fossem consideradas adaptadas às condições do meio natural que dispunham, não deixava de haver uma contradição interna nesse processo, na medida em que o próprio sucesso da adaptação do sistema acabava levando ao seu desaparecimento a longo prazo.

Ao longo do seu processo de evolução o sistema pode passar por diferentes fases: ora possui um grande valor adaptativo, onde as maneiras de fazê-lo funcionar (as práticas, as técnicas, as ferramentas, as relações de trabalho, por exemplo) se apresentam bem adaptadas e condizentes com as condições disponíveis, permitindo-lhe que se reproduza de maneira satisfatória; ora se apresenta completamente desadaptado mediante as transformações "naturais" que vão ocorrendo nas condições disponíveis durante sua evolução, transformações estas muitas vezes fruto do seu próprio sucesso adaptativo. Essa fase onde o sistema consegue manter-se adaptado, pode-se dizer, corresponde ao período em que funciona de maneira relativamente estável, onde ele próprio consegue regular suas contradições internas, ou seja, ele mantém certa independência em relação às variações dos seus componentes internos e das suas condições externas de funcionamento. Quando esse sistema não consegue mais fazer essa regulação das suas contradições internas de maneira que assegure seu funcionamento, pode chegar a um processo de desestruturação que pode levá-lo ao desaparecimento para, então, dar lugar a outro sistema (GODELIER, 1984).

Esse caráter contraditório do processo de adaptação que fala Godelier parece estar presente nessa escolha de incorporar elementos externos no sistema como meio para viabilizar sua diversificação: mesmo que a longo prazo essa incorporação possa levar a resultados negativos ao ambiente, no momento em que o processo está agora (curto/médio prazo) mostra-se adaptada para enfrentar as restrições existentes. Daí a combinação entre rompimento-permanência de uso de princípios da lógica moderna.

De qualquer forma, mesmo englobando essas contradições, as mudanças para diversificação e complexificação dos sistemas produtivos mostram uma tentativa de lidar de maneira diferente com o espaço e com o meio natural. Investir em cultivos de ciclos perenes ou em atividades que necessitem de infraestruturas permanentes, como a piscicultura, por exemplo, ou destinar áreas específicas para a 
atividade de roça indicam alterações na forma de gerir o espaço do estabelecimento. Já investir na reintrodução de árvores (ou introdução mesmo, no caso de famílias que foram assentadas nos pastos das fazendas), incorporar mais elementos nos sistemas de produção e promover maior integração entre eles, adotar novos tipos de manejo, ou seja, procurar (re)criar condições para favorecer ao reequilíbrio do sistema e melhor desenvolvimento dos processos ecológicos, demonstram um interesse de promover, de certa forma, um resgate da natureza completamente alterada ou de minimizar as pressões sobre os elementos do meio natural.

É preciso dizer que, pelo que se tem observado, levar a frente essas mudanças não tem sido uma tarefa fácil. Vários são os casos em que essas iniciativas não têm gerado resultados considerados pelos próprios agricultores como positivos ou satisfatórios, mas que mesmo assim têm sido mantidas por acharem que vale a pena continuar investindo nessa direção da diversificação. Como parte das dificuldades encontradas se relaciona com a questão da falta de conhecimento e informações sobre a "forma de fazer" as atividades introduzidas, então alguns agricultores estão agregando essa estratégia à outra complementar, de busca de ampliação de seus conhecimentos técnicos a partir da inserção em processos de capacitação. Neste sentido, observa-se que as famílias, a partir dos seus mais diferentes membros (marido, esposa, filhos/as), estão procurando se inserir em cursos técnicos promovidos por organizações e/ou instituições locais, com o intuito de se apropriar ou de aprimorar seus conhecimentos técnicos tanto de atividades que já estão sendo desenvolvidas quanto de outras atividades que têm a pretensão de desenvolver em seus estabelecimentos (OLIVEIRA, 2009; MARTINS; OLIVEIRA, 2010).

Mas, qual interesse dos agricultores em envidar tantos esforços em promover essa mudança para diversificação, em se adaptar? Aparentemente, mais do que motivações relacionadas a uma mudança de visão de natureza ou a atender às exigências legais das políticas ambientais ou aos estímulos de outras políticas, o interesse maior está vinculado a outro tipo de mudança que também parece estar em curso na região: a mudança nos projetos das famílias.

Estudos realizados no sudeste paraense, como os de Oliveira, Silva e Assis (2001), Oliveira et al. (2005) e Oliveira (2009), têm mostrado que há um arrefecimento do fluxo migratório nessa região, sendo atualmente mais característico o deslocamento interno de famílias, procurando uma melhor localização nesse espaço. As condições relativamente mais favoráveis do meio socioeconômico regional em termos de acesso aos mercados e às cidades, acesso a créditos e a serviços, oportunidades de emprego e, principalmente, maior estabilidade fundiária, têm estimulado os agricultores e suas famílias a mudarem seus projetos, no sentido 
de buscar sua reprodução social a partir da permanência no lugar, e não mais a partir da estratégia de migração, usualmente utilizada no passado.

A segurança da posse da terra, a melhoria relativa das condições de vida de várias famílias, a distância das novas áreas de floresta e, em parte, o começo de envelhecimento da população do campo (a primeira geração de famílias migrantes já está chegando ou já chegou à idade de aposentadoria), têm contribuído para mudar as relações dos agricultores com a terra e infundir essa vontade em permanecer e buscar alternativas que os possibilitem continuar produzindo na mesma área que possuem.

A complexificação dos sistemas de produção, principalmente a partir de atividades cuja produção se materializa em tempos mais longos ou que precisa de investimento em capital fixo - e também se poderiam acrescentar os investimentos na melhoria da qualidade de vida e conforto da família -, pode ser considerada um indício do estabelecimento de um processo mais amplo que Hurtienne (2005) denomina de estabilização relativa ou de mudança para permanência, conforme Carvalho (1999), já havia identificado em fronteiras agrícolas mais antigas do Estado, como o nordeste paraense. Para esse autor, a exploração da terra a partir de formas outras que não aquela da agricultura itinerante de corte-queima é demonstrativa dessa propensão ou, no mínimo, intenção à estabilização, à não migração.

No sudeste paraense, à semelhança do nordeste paraense (HURTIENNE, 2005), esse processo de superação da agricultura migratória a partir da incorporação de cultivos perenes e novas criações, da valorização dos produtos da floresta, do esforço de um manejo menos extensivo da pecuária e das iniciativas de integração das atividades, bem como a partir do uso de insumos externos, impõem novos desafios a serem enfrentados e novas limitações a serem transpostas. No entanto, por outro lado, oferecem também, pelo menos a curto/médio prazo, oportunidades do estabelecimento de sistemas menos vulneráveis.

As mudanças para permanência, a partir da diversificação, pode-se dizer, revelam, de certo modo, as mudanças que estão ocorrendo nas relações sociedadenatureza nessa região do sudeste paraense e na Amazônia Oriental de uma maneira mais ampla. Apesar de formas de exploração historicamente utilizadas (como a adoção do sistema mata $\rightarrow$ roça de corte-queima $\rightarrow$ pasto) ainda se fazerem presentes de maneira importante na região; o crescimento da quantidade de estabelecimentos baseados na complexidade, menos suscetíveis a perturbações e riscos, que procuram garantir a estabilidade do sistema para que mantenha no tempo e possibilite a permanência das famílias no lugar, demonstram uma busca dos agricultores em estabelecerem uma relação de maior aproximação com o meio natural que exploram. 


\section{CONSIDERAÇÕES FINAIS}

O processo de diversificação dos sistemas de produção em estabelecimentos familiares no sudeste paraense mostra os indícios de uma nova dinâmica se estabelecendo nessa área de fronteira. De uma agricultura itinerante e de uma estratégia de reprodução social baseada na migração para novas áreas de floresta, predominante no passado, atualmente os agricultores estão buscando formas alternativas de exploração do meio natural e de gestão do espaço através de uma mudança para diversificação, que possibilite atender ao seu novo projeto de viabilizar a reprodução social da família, a partir da permanência no lugar.

Esse processo de mudança tem incluído a introdução de novas atividades como forma de reaver a complexidade dos sistemas de produção, em muitos casos perdida ou reduzida, por conta da adoção de um padrão de exploração que levava à simplificação dos mesmos na pecuária, com o objetivo de torná-los mais sustentáveis. Pelo que se pôde observar, a estratégia para promover essa complexificação dos sistemas tem se pautado pela manutenção ou reestruturação do potencial produtivo do espaço, não necessariamente utilizando para isso o potencial do meio natural amazônico, fato constatado, por exemplo, pelo uso de espécies exógenas nas iniciativas de diversificação identificadas.

Além disso, observou-se também que, em vários casos, para possibilitar essa diversificação há a utilização de insumos externos característicos de uma agricultura intensiva, tais como mecanização e insumos químicos. No entanto, isso tem se dado muito mais por conta da limitação da capacidade de trabalho do que uma decisão consciente dos agricultores de quererem assumir o padrão moderno de agricultura.

Independentemente desses aspectos, o que se pretendeu mostrar foi que essas mudanças expressam, de certa maneira, um esforço dos agricultores em modificarem suas relações com o meio natural, procurando melhorar os manejos e a gestão do espaço e, principalmente, da fertilidade, sem as quais a durabilidade do sistema fica comprometida. As contradições que aparecem atreladas a essas mudanças, relacionadas ao fato de incorporarem elementos que potencialmente colocam em questionamento essa sustentabilidade, são passíveis de serem compreendidas na medida em que se considera que fazem parte do processo de adaptação pelos quais estão passando os agricultores e seus sistemas de produção. Não é possível ainda prever os resultados efetivos desse processo, visto que ainda se encontra em curso, mas ele certamente aponta para uma tentativa de aliar diversidade e sustentabilidade.

Compreender como está se dando essa diversificação no sudeste do Pará, suas características e limitações ajudam ainda na reflexão sobre o processo de estabilização relativa nas fronteiras da Amazônia, além de dar elementos para pensar a sustentabilidade do desenvolvimento rural da região. 


\section{REFERÊNCIAS}

ALMEIDA, J. A construção social de uma nova agricultura: tecnologia agrícola e movimentos sociais no sul do Brasil. Porto Alegre: Ed. UFRGS, 1999.

ALMEIDA, J. Da ideologia do progresso à idéia de desenvolvimento (rural) sustentável. In: ALMEIDA, J.; NAVARRO, Z. Reconstruindo a agricultura: ideias e ideais na perspectiva de um desenvolvimento rural sustentável. 2. ed. Porto Alegre: Ed. UFRGS, 1998.

ALTIERI, M. Agrocecologia: bases científicas para uma agricultura sustentável. Guaíba: Agropecuária, 2002.

ALTIERI, M. A.; NICHOLLS, C. I. Agroecologia: resgatando a agricultura orgânica a partir de um modelo industrial de produção e distribuição. Ciência \& Ambiente, Santa Maria, n. 27, p. 141-152, 2003.

BAREL, Y. La reproduction sociale: systèmes vivants, invariance et changement. Paris: Anthropos, 1973.

BECKER, B. Geopolítica da Amazônia. Estudos Avançados, São Paulo, v. 19, n. 53, p. 71-83, 2005.

BRANDEBURG, A. Modernidade, meio ambiente e interdisciplinaridade. Cadernos de Desenvolvimento e Meio Ambiente, Curitiba, n. 3, p. 49-59, 1996.

CAPORAL, F. R.; COSTABEBER, J. A. Agroecologia: alguns conceitos e princípios. Brasília: MDA/SAF/DATER-IICA, 2004.

CAPRA, F. As conexões ocultas: ciência para uma vida sustentável. 12. ed. São Paulo: Pensamento-Cultrix, 2002.

CARVALHO, V. R. V. de. Dinâmica inovativa entre camponeses do nordeste do Pará. Paper do NAEA, Belém, n. 88, p. 1-38, 1998.

CASTRO, E. Dinâmica socioeconômica e desmatamento na Amazônia. Novos Cadernos do NAEA, Belém, v. 8, n. 2, p.05-39, 2005.

CASTRO, E. Transformações ambientais na Amazônia: problemas locais e desafios internacionais. In: MENDES, A. D. Amazônia, terra e civilização: uma trajetória de 60 anos. v. 1, 2 ed. rev. aum. Belém: Banco da Amazônia, 2004.

COSTA, F. de A. et al. Agricultura familiar em transformação no nordeste paraense: o caso de Capitão Poço. Belém: UFPA/NAEA, 2000.

COSTA, F. de A. Formaçao agropecuária da Amazônia: os desafios do desenvolvimento sustentável. Belém: NAEA, 2000.

COSTA, F. de A. Ecologismo e questão agrária na Amazônia. Belém: SEPEQ/ NAEA/UFPA, 1992.

DIEGUES, A. C. O mito moderno da natureza intocada. 5. ed. São Paulo: Hucitec/ NUPAUB/USP, 2004. (Coleção Ecologia e Cultura).

EHLERS, E. Agricultura sustentável: origens e perspectivas de um novo paradigma. 2. ed. Guaíba: Agropecuária, 1999.

ELLIS, F. Household Strategies and Rural Livelihood Diversification. The Journal of Development Studies, London, v. 35, n. 1, p. 1-38, 1998.

ELLIS, F. Rural Livelihoods and Diversity in Developing Countries. Oxford: Oxford University Press, 2000. 
FERRY, L. A Nova Ordem Ecológica: a árvore, o animal, o homem. Rio de Janeiro: DIFEL, 2009.

FLORIT, L. A reinvenção social do natural: natureza e agricultura no mundo contemporâneo. Blumenau: Edifurb, 2004.

GOODMAN, D.; SORJ, B.; WILKINSON, J. Da lavoura às biotecnologias: agricultura e indústria no sistema internacional. Rio de Janeiro: Campus, 1990.

HURTIENNE, T. Agricultura familiar e desenvolvimento rural sustentável na Amazônia. Novos Cadernos do NAEA, Belém, v. 8, n. 1, p. 19-71, 2005.

KITAMURA, P. C. Agricultura Sustentável no Brasil: avanços e perspectivas. Ciência \& Ambiente, Santa Maria, n. 27, p. 07-28, 2003.

MARTINS, S. A.; OLIVEIRA, M. C. C. de. Mudanças nas práticas produtivas dos agricultores familiares do assentamento Lago Azul, no sudeste paraense. Revista da Faculdade de Ciências Agrárias de Marabá, Marabá, n. 1, p. 1-5, 2010.

McCORMICK, J. Rumo ao Paraíso: a história do movimento ambientalista. Rio de Janeiro: Relume Dumará, 1992.

MORIN, E. Os sete saberes necessários à educação do futuro. 8. ed. São Paulo: Cortez; Brasília: UNESCO, 2003.

OLIVEIRA JR., P. H. B. de. Notas sobre a história da agricultura através do tempo. Rio de Janeiro: FASE-PTA, 1989.

OLIVEIRA, M. C. C. de. Agricultura familiar e dinâmicas das relações sociedadenatureza em área de fronteira agrária na Amazônia oriental. 2009. 303f. Tese (Doutorado em Desenvolvimento Rural) - Faculdade de Ciências Econômicas, Universidade Federal do Rio Grande do Sul, Porto Alegre, 2009.

OLIVEIRA, M. C. C. de et al. Políticas de apoio à agricultura familiar e evolução do sistema agrário no sudeste do Pará. In: MOTA, D. M. da; SCHMITZ, H.; VASCONCELOS, H. E. M. Agricultura Familiar e abordagem sistêmica. Aracaju: Sociedade Brasileira de Sistemas de Produção, 2005.

OLIVEIRA, M. C. C. de; SILVA, W. R. da.; ASSIS, W. S de. Estudo sobre o processo de migração de agricultores familiares na área rural de Marabá. Marabá: LASAT, 2001. (Relatório de Pesquisa).

PÁDUA, J. A. Um sopro de destruição: pensamento político e crítica ambiental no Brasil escravista, 1786-1888. 2. ed. Rio de Janeiro: Zahar, 2004.

PINTO, A. de S. et al. Vamos fazer do campo um lugar bom para viver: reflexão sobre o processo de incentivo á diversificação da produção com perspectiva agroecológica nos municípios de Conceição do Araguaia e Santa Maria das Barreiras, Pará, Amazônia brasileira. Conceição do Araguaia: CPT Sul do Pará, 2010. (Relatório de Pesquisa).

RAYNAUT, C. O desenvolvimento e as lógicas da mudança: a necessidade de uma abordagem holística. Desenvolvimento e Meio Ambiente, Curitiba, n. 1, p.81-104, 1994. ROMEIRO, A. R. Meio ambiente e dinâmica de inovações na agricultura. São Paulo: Annablume; FAPESP, 1998.

VEIGA, J. E. da. O desenvolvimento agrícola: uma visão histórica. São Paulo: Edusp; Hucitec, 1991. (Estudos Rurais, 11). 